\title{
Patterns and socio-demographic correlates of domain-specific physical activities and their associations with adiposity in the China Kadoorie Biobank study
}

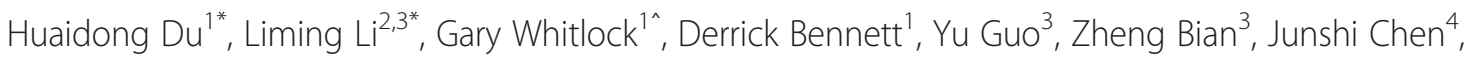
Paul Sherliker ${ }^{1}$, Ying Huang ${ }^{5}$, Ningmei Zhang ${ }^{6}$, Xiangyang Zheng ${ }^{7}$, Zhongxiao Li $i^{8}$, Ruying Hu${ }^{9}$, Rory Collins ${ }^{1}$, Richard Peto', Zhengming Chen', on behalf of the China Kadoorie Biobank (CKB) collaborative group

\begin{abstract}
Background: Domain-specific physical activities may have different correlates and health effects, but few large studies have examined these questions, especially their separate associations with adiposity.

Methods: We analysed cross-sectional data of 466605 adults without any prior chronic diseases, enrolled during 2004-8, from 10 diverse localities across China. Physical activity level in each of 4 domains (occupation, commuting, household, and active-recreation), calculated as metabolic equivalent (MET)-hr/day, was related to social-demographic factors and measures of adiposity (body mass index [BMI], waist circumference [WC], and bio-impedance derived percentage body fat), using multivariable linear and logistic regression models.
\end{abstract}

Results: The overall mean age was 50.8 years. The mean total physical activity was 21.7 MET-hr/day, mainly from occupation (62\%) and household chores (26\%), but little from active-recreation (4\%), with women having a much higher household activity than men. Older participants had a lower level of occupational activity but a higher level of household and active-recreational activity, particularly after retirement. There was no linear association of occupational activity with adiposity, but working women tended to have a lower adiposity (e.g. $1.0 \mathrm{~cm} \mathrm{WC}$ ) than non-working women. In men, there was an inverse and apparently linear association between adiposity and levels of both commuting-related and household activities, with $3 \mathrm{MET}$-hr/day associated with -0.11 and $-0.13 \mathrm{~kg} / \mathrm{m}^{2} \mathrm{BMl},-0.42$ and $-0.62 \mathrm{~cm} \mathrm{WC}$, and -0.28 and -0.33 percentage points of body fat, respectively. In women, only household activity showed a linear, but weaker, association with adiposity. A higher adiposity was observed among men and women with higher levels of active-recreational activity.

Conclusions: In Chinese adults, physical activity mainly involves occupation and housework, with little from active-recreational activity. Domain-specific physical activities varied by socio-demographic factors and had different associations with adiposity.

Keywords: Physical activity, Domain, Obesity, China, Biobank

\footnotetext{
* Correspondence: huaidong.du@ctsu.ox.ac.uk; Imlee@vip.163.com

Deceased

${ }^{1}$ Clinical Trial Service Unit and Epidemiological Studies Unit (CTSU), Nuffield

Department of Population Health, University of Oxford, Oxford, UK

${ }^{2}$ School of Public Health, Peking University Health Sciences Center, Beijing,

China

Full list of author information is available at the end of the article
} 


\section{Background}

The health benefits of physical activity have been well recognized [1]. However, studies to date have focused primarily on active-recreational activities, in spite of a large contribution to total physical activity level of occupational, household and commuting-related activities, particularly in low- and middle-income countries, such as China [2-4]. Activities from different domains may differ in their determinants [5-7] and knowledge about them could help to inform the development of effective physical activity interventions at a population level. Several studies have examined associations of physical activity from different domains with socio-demographic factors, but these were mainly in Western countries where people in general have an urban-industrial lifestyle. In China, although there has been a large shift from a labour-intensive lifestyle to a more sedentary lifestyle over the past few decades, patterns of physical activity still differ greatly from those in the Western countries, with, for example, higher participation in leisure-time and household activity among older people in China [8], contrasting that seen in most Western populations [6].

A higher level of physical activity has been deemed as beneficial for preventing weight gain and obesity. Question remains, however, about the separate associations of domain-specific physical activities with adiposity and other health-related outcomes. Several studies have attempted to address these issues but the findings were inconsistent, with some showing inverse association between commuting-related activity and adiposity in various populations including Chinese [9], South Asians [10], and Americans [11] whereas others showing no association [12], an inverse association $[2,13]$, or a positive association [14] between occupational activity and adiposity. Largescale epidemiological studies comparing simultaneously the associations of physical activity from four major domains with measures of adiposity are still lacking.

To fill this evidence gap, we report the findings of a cross-sectional investigation using data from the China Kadoorie Biobank (CKB), a prospective observational study of over 500000 adults recruited from 10 diverse areas in China [15,16]. The aims of this report are: 1) to determine the socio-demographic correlates of physical activity from occupation, commuting, housework and active- recreation; 2) to investigate the associations of domain-specific activity with different measures of adiposity including body mass index (BMI), waist circumference (WC) and percentage body fat.

\section{Methods}

\section{Study design and participants}

Detailed information about the CKB study design, survey methods and participant characteristics has been reported previously $[15,16]$. In brief, all permanent residents aged
35-74 years in 10 geographically defined areas (5 urban and 5 rural) of China, identified through public registry records, were eligible to take part in the study. The areas were selected so as to cover wide spectra of risk exposures and disease patterns, and for logistical convenience, but were not intended to be representative of China as a whole. The baseline survey was conducted between June 2004 and July 2008. Invitation letters and study information leaflets were delivered door-to-door by local community leaders and health workers following extensive publicity campaigns. About one in three of the eligible residents (33\% rural, 27\% urban) participated. To encourage participation, those few individuals aged $30-34$ or $75-79$ years were not turned away [16]. In total, 512891 participants (210 222 men and nearly all Han Chinese) were enrolled in the CKB.

For the current analyses, we excluded those who had a history of heart disease $(n=15472)$, stroke $(n=8884)$, tuberculosis $(\mathrm{n}=7660)$, chronic obstructive pulmonary disease ( $n=13289)$, and/or cancer ( $n=2577)$; those who answered all questions in the physical activity questionnaire with zero $(n=81)$; those who reported spending more than 20 hours daily on all waking activities ( $\mathrm{n}=813$ ); and those who gave implausible or conflicting answers to occupational and commuting-related questions (e.g. who reported not working but had non-zero commuting-related physical activity) ( $\mathrm{n}=1418)$. After these exclusions, 466605 participants remained in this cross-sectional analysis.

The study was approved by the ethics committees of the University of Oxford and the Chinese Center for Disease Control and Prevention (CDC). In addition, ethics approval was obtained from the institutional research board at the local CDC in each of the 10 areas. Written informed consent was obtained from all participants.

\section{Data collection}

The baseline data collection took place in temporary assessment clinics specially set up in the local communities for this study. An interviewer-administered computerised questionnaire was used to collect information on socio-demographic factors (e.g. education, annual household income, and occupation), lifestyle factors (e.g. smoking, drinking, diet and physical activity), and medical history.

Detailed information on physical activity questions and methods used to derive domain-specific physical activity levels, in metabolic equivalents (MET)-hr/day, have been reported previously [17]. In brief, questions about physical activity were adapted from validated questionnaires used in several other studies in Western [18] and Chinese populations [19], with some additional modifications following a CKB pilot study. To quantify the amount of physical activity, metabolic equivalents (METs) 
from the 2011 update of a major compendium of physical activities [20] were used. Occupational activity included all physical activities performed during paid employment; commuting-related activity was the physical activity performed during the journeys between home and work, without including the transportation for other purposes; household activity included activities spent on household chores; and active-recreational activity included activities spent on sports during leisure time, but not sedentary leisure-time activities (mainly TV viewing) [17].

Body weight, standing height, WC and body fat percentage were measured by trained health workers while participants wore light clothes and no shoes. Standing height was measured to the nearest $0.1 \mathrm{~cm}$ using a stadiometer, and WC was measured with a soft non-stretchable tape at midway between the lowest rib and the iliac crest, also to the nearest $0.1 \mathrm{~cm}$. Weight and percentage body fat were estimated using a bioelectrical impedance device (TANITA-TBF-300GS, Tanita Corp., Tokyo, Japan). BMI was calculated as the weight in kilograms divided by the square of standing height in meters.

\section{Statistical analyses}

For each of the four domains of physical activity, participants were first divided into two groups: performing no such activity or some activity; and the proportions of participants with no activity by socio-demographic factors were estimated separately for men and women using logistic regression models, adjusting for age (in 5-year intervals) and study area, where appropriate. Among those who had some activity from a specific domain, multiple linear regression models were used to estimate the age- and areaadjusted mean levels of activity by socio-demographic factors.

The adjusted mean levels (and 95\% CIs) of adiposity measures in 4 groups of each domain-specific physical activity (zero, low, moderate or high) were estimated using multiple linear regression models with adjustment for age, study area (10 study areas), education (no formal education, primary school, middle or high school, and college or university), annual household income $(<10000$, 10 000-19 999, 20 000-34 999, and $\geq 35000$ yuan), sedentary leisure time (hr/day), smoking (never, exregular, occasional and current smokers), alcohol intake (never, ex-regular, occasional and current drinkers) and other domain-specific activities (MET-hr/day). Analyses were performed separately for men and women and, if an approximately linear association was observed, differences in adiposity per 3 MET-hr/day of domain-specific physical activity were also examined using multiple linear regression with heterogeneity assessed by $x^{2}$ statistics, $P$ values from Cochran $\mathrm{Q}$ tests, and $I^{2}$ statistics (i.e. the variation in pooled estimates accounted for by heterogeneity rather than by chance) [21]. All statistical analyses were conducted using SAS 9.2 (SAS Institute Inc., Cary, NC, USA).

\section{Results}

Of the 466605 participants included, the mean baseline age was 50.8 years, $40.4 \%$ were men, and $42.5 \%$ came from urban areas. Occupational activity was the largest domain, accounting for $76 \%$ and $52 \%$ of total physical activity in men and women respectively, and activerecreational activity was the smallest, accounting for less than $4 \%$ of total physical activity in both sexes. Nearly all women but only about $79 \%$ of men engaged in household work with the mean activity level in women being more than 2.5 times as high as in men (7.7 vs. $2.9 \mathrm{MET}$-hr/day). Women had higher mean percentage body fat ( $32 \%$ vs. $22 \%)$, higher mean BMI (23.8 vs. $\left.23.4 \mathrm{~kg} / \mathrm{m}^{2}\right)$, but lower mean WC (78.8 vs. $\left.81.9 \mathrm{~cm}\right)$ than men (Table 1).

In both sexes, age was strongly and inversely associated with proportion of having and the mean levels of occupational activity. Due to retirement, the proportion of non-working people increased dramatically at 60-69 years for men (from $12.5 \%$ at $50-59$ years to $49.3 \%$ ) and 50-59 years for women (from $13.4 \%$ at $40-49$ years to $45.6 \%)$. At the same time, mean levels of occupational activity, among those still working, greatly decreased (Table 2). An opposite trend was observed for activerecreational activity; those aged 70-79 years were $\sim 3.6$ times more likely to perform regular physical exercise than those aged 30-39 years. Their mean level of exercise was also higher than those younger than 60 years (for men) or 50 years (for women).

Compared with rural participants, urban participants were more likely to participate in all three nonoccupational activities and had a higher mean level of active-recreational activity, but lower mean levels of commuting-related and household activity. On the other hand, mean level of occupational activity was higher in rural men and urban women as compared to their corresponding counterparts. Rural farmers do not have to retire at certain ages, therefore there was a much smaller proportion of non-working people in rural than in urban areas (Table 2). Across the 10 study areas, overall mean level of occupational activity was the highest in Zhejiang (a rural costal area) in both men and women, and the lowest in men from Haikou (an urban tropical area) and women from Henan (a rural inland area). Commutingrelated activity was much higher in Gansu, a rural inland area in the west of China, than in other areas. With regard to mean level of household activity, the highest was found in women from Gansu and the lowest was in men from Henan (Additional file 1: Figure S1).

Factory workers had the highest mean level of occupational activity (25.9 MET-hr/day in men and 24.1 in 
Table 1 Main characteristics of study participants

\begin{tabular}{lccc}
\hline Characteristics & $\begin{array}{c}\text { Men } \\
(\mathbf{n}=\mathbf{1 8 8} 6 \mathbf{6 4})\end{array}$ & $\begin{array}{c}\text { Women } \\
(\mathbf{n}=\mathbf{2 7 7} \mathbf{9 5 8})\end{array}$ & $\begin{array}{c}\text { Total } \\
(\mathbf{n}=\mathbf{1 8 8} 6 \mathbf{6 4})\end{array}$ \\
\hline Age (years), \% & & & \\
$30-39$ & 15.2 & 16.9 & 16.2 \\
$40-49$ & 30.0 & 32.2 & 31.3 \\
$50-59$ & 30.6 & 30.8 & 30.7 \\
$60-69$ & 17.8 & 15.2 & 16.2 \\
$70-79$ & 6.5 & 4.8 & 5.5 \\
Mean (SD) & $51.5(10.7)$ & $50.3(10.3)$ & $50.8(10.5)$ \\
Residence, \% & & & \\
Urban & 42.6 & 43.3 & 43.0 \\
Rural & 57.4 & 56.7 & 57.0 \\
Occupational physical activity (MET-hr/day), \% & \\
0 & 18.1 & 34.7 & 28.0 \\
$0.1-10$ & 18.0 & 20.7 & 19.6 \\
$10.1-$ 20 & 25.5 & 23.1 & 24.1 \\
> 20 & 38.4 & 21.5 & 28.3 \\
Mean (SD) & $17.3(14.9)$ & $10.9(12.5)$ & $13.5(13.9)$
\end{tabular}

Commuting-related physical activity (MET-hr/day), \%

$\begin{array}{lccc}0 & 31.4 & 47.3 & 40.9 \\ 0.1-1.5 & 23.5 & 17.9 & 20.1 \\ 1.6-3.0 & 26.0 & 20.2 & 22.6 \\ >3.0 & 19.1 & 14.6 & 16.4 \\ \text { Mean (SD) } & 1.9(2.4) & 1.4(2.2) & 1.6(2.3) \\ \text { Household physical activity }(\text { MET-hr/day) } & & \\ 0 & 21.0 & 0.7 & 8.9 \\ 0.1-4.0 & 54.5 & 15.8 & 31.4 \\ 4.1-8.0 & 17.4 & 31.8 & 26.0 \\ >8.0 & 7.0 & 51.8 & 33.7 \\ \text { Mean (SD) } & 2.9(2.8) & 7.7(3.9) & 5.7(4.2)\end{array}$

Active-recreational physical activity (MET-hr/day), \%

\begin{tabular}{lccc}
0 & 79.0 & 80.4 & 79.8 \\
$0.1-2.0$ & 6.9 & 5.8 & 6.2 \\
$2.0-4.0$ & 6.8 & 6.5 & 6.7 \\
$>4.0$ & 7.2 & 7.3 & 7.3 \\
$\quad$ Mean (SD) & $0.8(2.2)$ & $0.8(2.2)$ & $0.8(2.2)$ \\
$\begin{array}{l}\text { Total physical activity } \\
\text { (MET-hr/day) }\end{array}$ & $22.8(15.1)$ & $20.9(12.8)$ & $21.7(13.8)$ \\
Sedentary leisure time & $3.1(1.5)$ & $2.9(1.5)$ & $3.0(1.5)$ \\
(hr/day) & & & \\
Body mass index $\left(\mathrm{kg} / \mathrm{m}^{2}\right)^{1}$ & $23.4(3.2)$ & $23.8(3.4)$ & $23.6(3.3)$ \\
Waist circumference $(\mathrm{cm})$ & $81.9(9.7)$ & $78.8(9.4)$ & $80.1(9.6)$ \\
Percentage body fat $(\%)^{2}$ & $22.0(6.2)$ & $32.0(7.1)$ & $28.0(8.3)$ \\
\hline
\end{tabular}

SD: standard deviation.

${ }^{1} 2$ participants with missing values.

${ }^{2} 214$ participants with missing values. women), followed by sales \& self-employed (21.6 in men and 21.7 in women) (Table 3). Although mean level of commuting-related activity did not vary greatly across different occupations (2.1-2.9 MET-hr/day), proportion of non-commuting sales \& self-employed was 9 times (in men) or 21 times (in women) as high as that of noncommuting farmers, and 3 times (in both men and women) as high as non-commuting factory workers. The mean levels of household and active-recreational activity were the highest in those not in paid occupation, including those retired and unemployed individuals and home makers. They also had a higher tendency to perform active-recreational activity, i.e. lower proportion of no such activity. For both men and women, sales \& selfemployed group had the lowest rate of household activity participating. In both sexes, education was associated inversely with mean levels of occupational, commutingrelated and household activity but positively with proportion engaged in active-recreational activity. A lower proportion of non-working people was observed among those with a college or university education, particularly in women. A higher level of education was associated with a lower mean level of household activity, a higher proportion of men but lower proportion of women participating in household tasks. People with college or university education were 4 times more likely to perform regular physical exercise than those with no formal education. Household income was also positively, though to a lesser extent compared with education, associated with proportion of participating in active-recreational activity. However, no clear linear association of either education or household income with mean level active-recreational activity was observed. $P$ values for heterogeneity for all of these associations were $<0.0001$ (Table 3).

Occupational activity was not linearly associated with any of the adiposity measures (Figure 1, Figure 2 and Figure 3). However, men with the highest level of occupational activity (i.e. > 20 MET-hr/day) had the lowest level of adiposity and women with the highest level of occupational activity also had the lowest percentage body fat. Working women were in general leaner than non-working women, in terms of all three adiposity measures, especially WC which was $1.0 \mathrm{~cm}$ smaller in working than in non-working women.

In men, both commuting-related activity and household activity were inversely associated with adiposity regardless of how it is measured (Figure 1A, Figure 2A and Figure 3A). Men with high level of commuting (mean $5.7 \mathrm{MET}-\mathrm{hr} /$ day) had $0.4 \mathrm{~kg} / \mathrm{m}^{2}$ lower BMI, $1.6 \mathrm{~cm}$ smaller $\mathrm{WC}$, and 1.0\% lower percentage body fat than those not commuting. Similar difference in adiposity was also seen in men between high (9.6 MET-hr/day) and no household activity: $0.4 \mathrm{~kg} / \mathrm{m}^{2}, 1.3 \mathrm{~cm}$, and $1.0 \%$, respectively. As shown in Additional file 2: Figure S2, 
Table 2 Levels of domain-specific physical activity by age and area ${ }^{1}$

\begin{tabular}{|c|c|c|c|c|c|c|c|c|c|}
\hline \multirow[t]{3}{*}{ Characteristics } & \multirow[t]{3}{*}{$\mathrm{n}$} & \multicolumn{8}{|c|}{ Physical activity } \\
\hline & & \multicolumn{2}{|c|}{ Occupational } & \multicolumn{2}{|c|}{ Commuting-related } & \multicolumn{2}{|c|}{ Household } & \multicolumn{2}{|c|}{ Active-recreational } \\
\hline & & $\begin{array}{l}\% \text { no } \\
\text { activity }\end{array}$ & $\begin{array}{l}\text { Mean MET-hr/ } \\
\text { day }\left(\text { SD) }^{2}\right.\end{array}$ & $\begin{array}{c}\% \text { no } \\
\text { activity }^{3}\end{array}$ & $\begin{array}{l}\text { Mean MET-hr/ } \\
\text { day (SD) }\end{array}$ & $\begin{array}{l}\text { \% no } \\
\text { activity }\end{array}$ & $\begin{array}{l}\text { Mean MET-hr/ } \\
\text { day }\left(\text { SD) }^{2}\right.\end{array}$ & $\begin{array}{l}\text { \% no } \\
\text { activity }\end{array}$ & $\begin{array}{l}\text { Mean MET-hr/ } \\
\text { day (SD) }{ }^{2}\end{array}$ \\
\hline \multicolumn{10}{|l|}{ Men } \\
\hline \multicolumn{10}{|l|}{ Age, years } \\
\hline $30-39$ & 28694 & 1.7 & $23.6(12.8)$ & 17.8 & $2.5(2.2)$ & 24.0 & $2.9(2.6)$ & 88.4 & $3.1(3.2)$ \\
\hline $40-49$ & 56513 & 2.9 & $23.1(12.8)$ & 16.7 & $2.6(2.2)$ & 22.8 & $3.2(2.6)$ & 87.5 & $3.2(3.2)$ \\
\hline $50-59$ & 57721 & 12.5 & $20.9(12.8)$ & 15.2 & $2.9(2.1)$ & 20.9 & $3.7(2.6)$ & 79.7 & $3.9(3.2)$ \\
\hline $60-69$ & 33512 & 49.3 & $15.2(12.9)$ & 15.6 & $2.8(2.2)$ & 16.9 & $4.3(2.6)$ & 62.7 & $4.5(3.2)$ \\
\hline $70-79$ & 12207 & 68.1 & $10.3(12.8)$ & 16.4 & $2.6(2.2)$ & 17.5 & $4.3(2.6)$ & 58.1 & $4.4(3.2)$ \\
\hline \multicolumn{10}{|l|}{ Region } \\
\hline Rural & 108347 & 4.8 & $21.5(13.6)$ & 19.4 & $2.9(2.5)$ & 23.7 & $3.8(2.6)$ & 91.9 & $2.7(3.2)$ \\
\hline Urban & 80300 & 36.1 & $20.4(13.7)$ & 10.5 & $2.4(2.5)$ & 17.4 & $3.4(2.6)$ & 61.4 & $4.3(3.2)$ \\
\hline \multicolumn{10}{|l|}{ Women } \\
\hline \multicolumn{10}{|l|}{ Age, years } \\
\hline $30-39$ & 47033 & 9.0 & $18.4(10.3)$ & 19.4 & $2.6(1.9)$ & 1.1 & $6.8(3.6)$ & 90.5 & $3.0(3.1)$ \\
\hline $40-49$ & 89625 & 13.4 & $18.4(10.3)$ & 19.1 & $2.8(1.9)$ & 0.7 & $7.1(3.6)$ & 87.2 & $3.6(3.1)$ \\
\hline $50-59$ & 85692 & 45.6 & $14.8(10.3)$ & 18.9 & $2.8(1.9)$ & 0.4 & 8.7 (3.6) & 76.6 & $4.5(3.1)$ \\
\hline $60-69$ & 42206 & 70.1 & $11.7(10.3)$ & 21.2 & 2.7 (1.9) & 0.6 & $8.4(3.6)$ & 66.2 & $4.3(3.1)$ \\
\hline $70-79$ & 13402 & 85.8 & $8.0(10.2)$ & 21.3 & $2.6(1.9)$ & 1.7 & $7.6(3.6)$ & 68.4 & $4.0(3.1)$ \\
\hline \multicolumn{10}{|l|}{ Region } \\
\hline Rural & 157557 & 17.1 & $15.8(11.7)$ & 21.7 & $2.9(2.4)$ & 0.5 & $8.4(3.7)$ & 93.9 & $2.8(3.1)$ \\
\hline Urban & 120401 & 57.7 & $18.8(11.8)$ & 13.8 & $2.5(2.4)$ & 0.9 & $7.0(3.7)$ & 62.7 & $4.4(3.1)$ \\
\hline
\end{tabular}

Values were adjusted for age and study area (where appropriate). All P for heterogeneity across subgroups $<0.0001$ for all.

${ }^{2}$ Least square means (standard deviations) among those participants who have that domain-specific physical activity.

${ }^{3}$ The proportion was calculated among working people only.

per 3 MET-hr/day higher commuting-related activity was associated with 0.13 (95\% CI: $0.11,0.15) \mathrm{kg} / \mathrm{m}^{2}$ lower BMI, $0.62(0.56,0.68) \mathrm{cm}$ smaller WC, and 0.16 $(0.12,0.20)$ percentage point less body fat. Household activity had a similar association with BMI and percentage body fat (3 MET-hr/day was associated with -0.11 $(-0.10,-0.13) \mathrm{kg} / \mathrm{m}^{2}$ and $-0.18(-0.15,-0.21)$ percentage point), but its association with WC was much weaker compared to that of commuting-related activity (3 MET-hr/day was related to $-0.42(-0.38,-0.47) \mathrm{cm})$.

Female commuters overall had a much lower degree of adiposity than those who did not commute $\left(0.5 \mathrm{~kg} / \mathrm{m}^{2}\right.$ BMI, $1.0 \mathrm{~cm} \mathrm{WC}$, and $1.1 \%$ body fat). However, there was a non- linear association between commutingrelated activity and adiposity and women who had a moderate amount of commuting-related activity (1.63.0 MET-hr/day) tended to have the lowest level of adiposity (Figure 1B, Figure $2 \mathrm{~B}$ and Figure $3 \mathrm{~B}$ ). In women, the inverse association between household activity and adiposity, though statistically significant, was much weaker than that in men. Restricting the analyses only to women who had some household activity (only $0.7 \%$ women were excluded), each 3 MET-hr/day higher household activity was associated with $0.02(0.01,0.03) \mathrm{kg} / \mathrm{m}^{2}$ lower BMI, $0.09(0.06,0.12) \mathrm{cm}$ smaller WC, and 0.07 $(0.05,0.10)$ percentage point less body fat (Additional file 3: Figure S3).

In both men and women, those who reported performing some regular exercise during their leisure time tended to have a higher level of adiposity than those who did not $\left(0.4 \mathrm{~kg} / \mathrm{m}^{2}\right.$ BMI, $0.9 \mathrm{~cm} \mathrm{WC}$ and $0.4 \%$ body fat in men and $0.4 \mathrm{~kg} / \mathrm{m}^{2}$ BMI, $0.7 \mathrm{~cm} \mathrm{WC}$ and $0.6 \%$ body fat in women) (Figure 1, Figure 2 and Figure 3).

\section{Discussion}

This is the first well-powered and detailed study of domain-specific physical activity in relation to sociodemographic factors and adiposity among Chinese men and women from both urban and rural areas. With a much larger and more diverse population, our study confirms the findings reported in most previous studies based on people from China and other low- and middleincome countries $[8,22-24]$ in the following aspects: occupational and household physical activity are the two 
Table 3 Levels of domain-specific physical activity by socioeconomic factors ${ }^{1}$

\begin{tabular}{|c|c|c|c|c|c|c|c|c|c|}
\hline \multirow[t]{3}{*}{ Characteristics } & \multirow[t]{3}{*}{$\mathbf{n}$} & \multicolumn{8}{|c|}{ Physical activity } \\
\hline & & \multicolumn{2}{|c|}{ Occupational } & \multicolumn{2}{|c|}{ Commuting-related } & \multicolumn{2}{|c|}{ Household } & \multicolumn{2}{|c|}{ Active-recreational } \\
\hline & & $\begin{array}{c}\% \text { no } \\
\text { activity }\end{array}$ & $\begin{array}{l}\text { Mean MET-hr/ } \\
\text { day (SD) })^{2}\end{array}$ & $\begin{array}{c}\% \text { no } \\
\text { activity }^{3}\end{array}$ & $\begin{array}{l}\text { Mean MET-hr/ } \\
\text { day (SD) })^{2}\end{array}$ & $\begin{array}{c}\% \text { no } \\
\text { activity }\end{array}$ & $\begin{array}{l}\text { Mean MET-hr/ } \\
\text { day (SD) })^{2}\end{array}$ & $\begin{array}{c}\% \text { no } \\
\text { activity }\end{array}$ & $\begin{array}{l}\text { Mean MET-hr/ } \\
\text { day }(S D)^{2}\end{array}$ \\
\hline \multicolumn{10}{|l|}{ Men } \\
\hline \multicolumn{10}{|l|}{ Occupation } \\
\hline Farmer & 84124 & 1.6 & $19.6(16.4)$ & 5.7 & $2.9(2.9)$ & 20.7 & $3.6(3.3)$ & 90.3 & $3.3(4.5)$ \\
\hline Factory worker & 38389 & 0 & $25.9(16.1)$ & 16.9 & $2.6(2.8)$ & 19.0 & $3.3(3.1)$ & 79.3 & $3.2(3.7)$ \\
\hline Sales \& others ${ }^{4}$ & 19450 & 0 & $21.6(13.6)$ & 52.4 & $2.6(2.3)$ & 28.2 & $3.2(2.7)$ & 76.0 & $3.4(3.3)$ \\
\hline Professionals & 13839 & 0 & $16.4(13.7)$ & 27.2 & $2.1(2.4)$ & 21.5 & $3.1(2.7)$ & 61.5 & $3.4(3.4)$ \\
\hline Retired \& others ${ }^{5}$ & 32845 & 100 & - & - & - & 19.6 & $4.4(3.1)$ & 58.7 & $4.6(3.8)$ \\
\hline \multicolumn{10}{|l|}{ Highest education } \\
\hline No formal education & 16387 & 11.4 & $22.5(14.2)$ & 11.8 & $3.1(2.4)$ & 22.2 & $3.8(2.8)$ & 91.1 & $3.8(3.3)$ \\
\hline Primary school & 62101 & 15.7 & $22.2(14.0)$ & 14.4 & $2.9(2.4)$ & 20.9 & $3.8(2.8)$ & 85.7 & $3.8(3.4)$ \\
\hline Middle or high school & 95869 & 21.6 & $21.0(13.7)$ & 17.9 & $2.6(2.3)$ & 21.0 & $3.5(2.7)$ & 75.5 & $4.0(3.2)$ \\
\hline College or university & 14290 & 13.0 & $14.8(13.9)$ & 19.0 & $2.2(2.4)$ & 19.8 & $3.2(2.8)$ & 59.0 & $3.9(3.3)$ \\
\hline \multicolumn{10}{|c|}{ Annual household income (yuan) } \\
\hline$<10000$ & 48718 & 20.0 & $21.8(15.3)$ & 13.2 & $3.0(2.6)$ & 18.1 & $4.0(3.0)$ & 86.7 & $3.8(3.4)$ \\
\hline $10000-19999$ & 53248 & 21.3 & $22.3(13.0)$ & 15.0 & $2.8(2.2)$ & 21.6 & $3.7(2.6)$ & 80.4 & $4.0(3.2)$ \\
\hline $20000-34999$ & 48151 & 16.3 & $21.4(13.6)$ & 15.6 & $2.6(2.3)$ & 21.0 & $3.5(2.7)$ & 77.1 & $3.9(3.2)$ \\
\hline$\geq 35000$ & 38530 & 13.6 & $18.6(14.1)$ & 22.5 & $2.3(2.4)$ & 23.9 & $3.2(2.8)$ & 69.5 & $3.9(3.3)^{6}$ \\
\hline \multicolumn{10}{|l|}{ Women } \\
\hline \multicolumn{10}{|l|}{ Occupation } \\
\hline Farmer & 116776 & 2.2 & $13.8(12.5)$ & 3.6 & $2.8(2.5)$ & 0.2 & $8.0(4.4)$ & 92.3 & $3.4(4.6)$ \\
\hline Factory worker & 31190 & 0 & $24.1(12.2)$ & 25.1 & $2.7(2.4)$ & 1.3 & $5.4(3.9)$ & 83.4 & $3.1(3.4)$ \\
\hline Sales \& others ${ }^{4}$ & 24826 & 0 & $21.7(11.6)$ & 74.3 & $2.8(2.2)$ & 2.3 & $5.9(3.7)$ & 83.4 & $3.2(3.2)$ \\
\hline Professionals & 11304 & 0 & $15.0(11.1)$ & 41.6 & $2.5(2.2)$ & 1.6 & 5.5 (3.6) & 67.8 & $3.2(3.3)$ \\
\hline Retired \& others ${ }^{5}$ & 93862 & 100 & - & - & - & 0.5 & $9.1(4.1)$ & 65.4 & $4.5(3.4)$ \\
\hline \multicolumn{10}{|l|}{ Highest education } \\
\hline No formal education & 70147 & 27.8 & $16.5(12.5)$ & 18.2 & $3.0(2.4)$ & 0.6 & $8.1(4.4)$ & 90.7 & $3.7(3.5)$ \\
\hline Primary school & 87196 & 35.2 & $17.4(10.7)$ & 19.3 & $2.8(2.0)$ & 0.6 & 7.9 (3.8) & 84.7 & $4.0(3.3)$ \\
\hline Middle or high school & 108625 & 40.9 & $17.1(11.7)$ & 20.2 & $2.6(2.2)$ & 0.7 & $7.6(4.1)$ & 72.4 & $4.3(3.3)$ \\
\hline College or university & 11990 & 14.2 & $11.4(11.4)$ & 18.3 & $2.3(2.2)$ & 1.1 & $6.4(3.9)$ & 61.8 & $3.9(3.2)^{6}$ \\
\hline \multicolumn{10}{|c|}{ Annual household income (yuan) } \\
\hline$<10000$ & 82776 & 32.5 & $16.5(12.3)$ & 19.8 & $2.8(2.4)$ & 0.5 & $7.7(4.2)$ & 86.6 & $4.0(3.3)$ \\
\hline $10000-19999$ & 81908 & 37.2 & $17.1(10.4)$ & 17.7 & $2.8(1.9)$ & 0.6 & $7.9(3.7)$ & 81.8 & $4.1(3.1)$ \\
\hline $20000-34999$ & 67527 & 33.6 & $17.3(11.3)$ & 17.0 & $2.7(2.1)$ & 0.7 & $7.7(3.8)$ & 78.1 & $4.1(3.1)$ \\
\hline$\geq 35000$ & 45747 & 35.7 & $15.7(11.3)$ & 24.4 & $2.5(2.1)$ & 1.1 & $7.7(3.9)^{6}$ & 70.3 & $4.1(3.2)^{6}$ \\
\hline
\end{tabular}

${ }^{1}$ Values were adjusted for age and study area, $P$ for heterogeneity $<0.0001$ for all domain-specific physical activities.

${ }^{2}$ Least square means (standard deviations) among those participants who have that domain-specific physical activity.

${ }^{3}$ The proportion was calculated among working people only.

${ }^{4}$ Including sales, self-employed and people in other un-specified occupations.

Including those retired, un-employed and home makers.

${ }^{6} P$ for trend across subgroups $>0.05$, all other $P<0.0001$.

largest domains and women on average had a much greater level of household activity than men; older participants had a lower level of occupational activity but a higher level of household and active-recreational activity, particularly after retirement, due perhaps mainly to more available time for such activities. This study also 


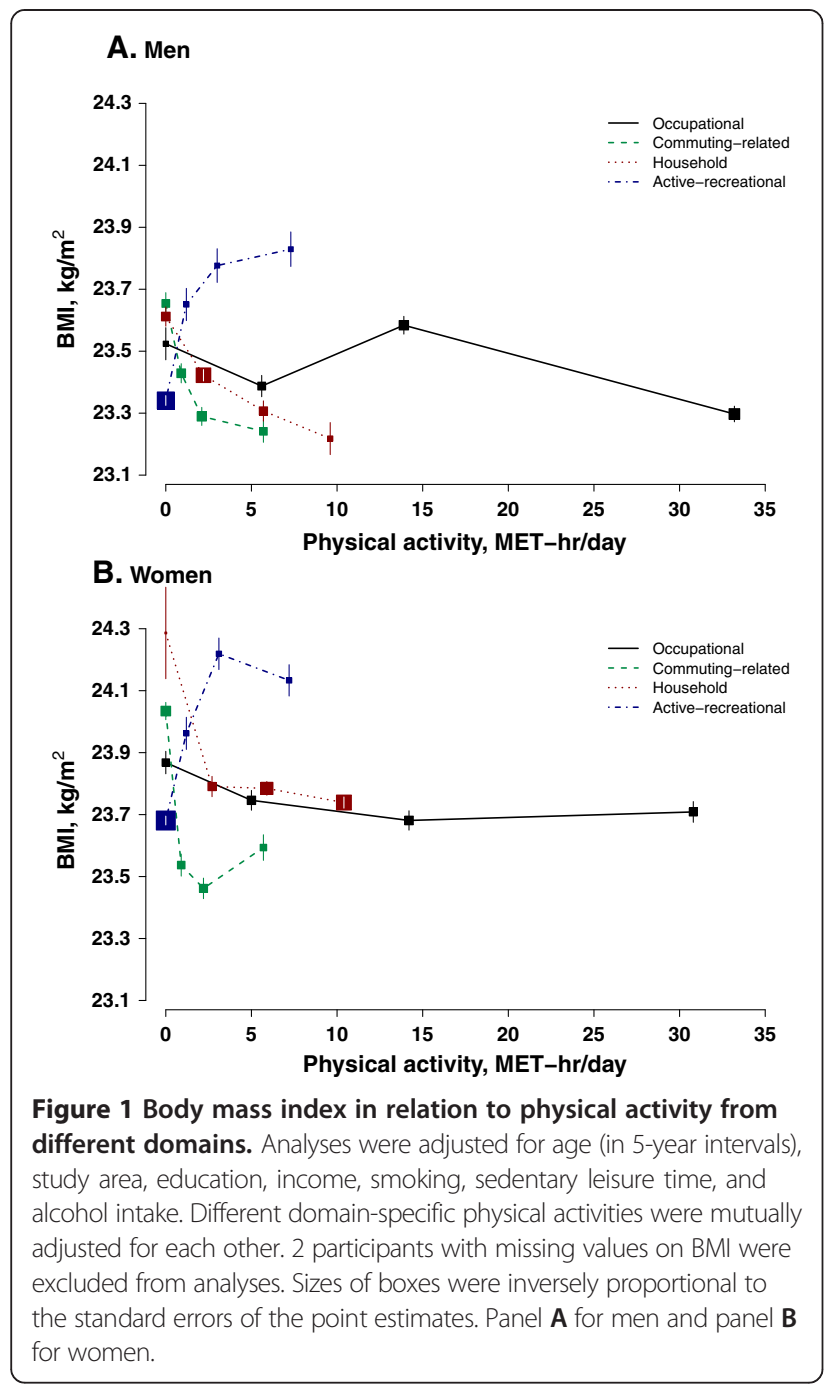

found that the proportion of people performing activerecreational activity (22\% of our participants) among Chinese adults is much lower than that typically seen in Western populations $[25,26]$, which may be attributable partly to less available time and partly to a lack of awareness about the importance of such activity, especially in rural areas $[8,22]$.

Although our study population is not intended to be representative of China as a whole or of any particular province [16], the associations observed, e.g. household activity in relation to adiposity, may still be generalisable to other settings or populations at large $[27,28]$. The true association might even be stronger than that observed in this study since the 10 study areas probably do not include China's full regional extremes.

An unexpected finding in our study was the lack of apparent association of occupational activity, the largest domain of total physical activity, with adiposity. Previous studies have provided mixed findings on this. For example,

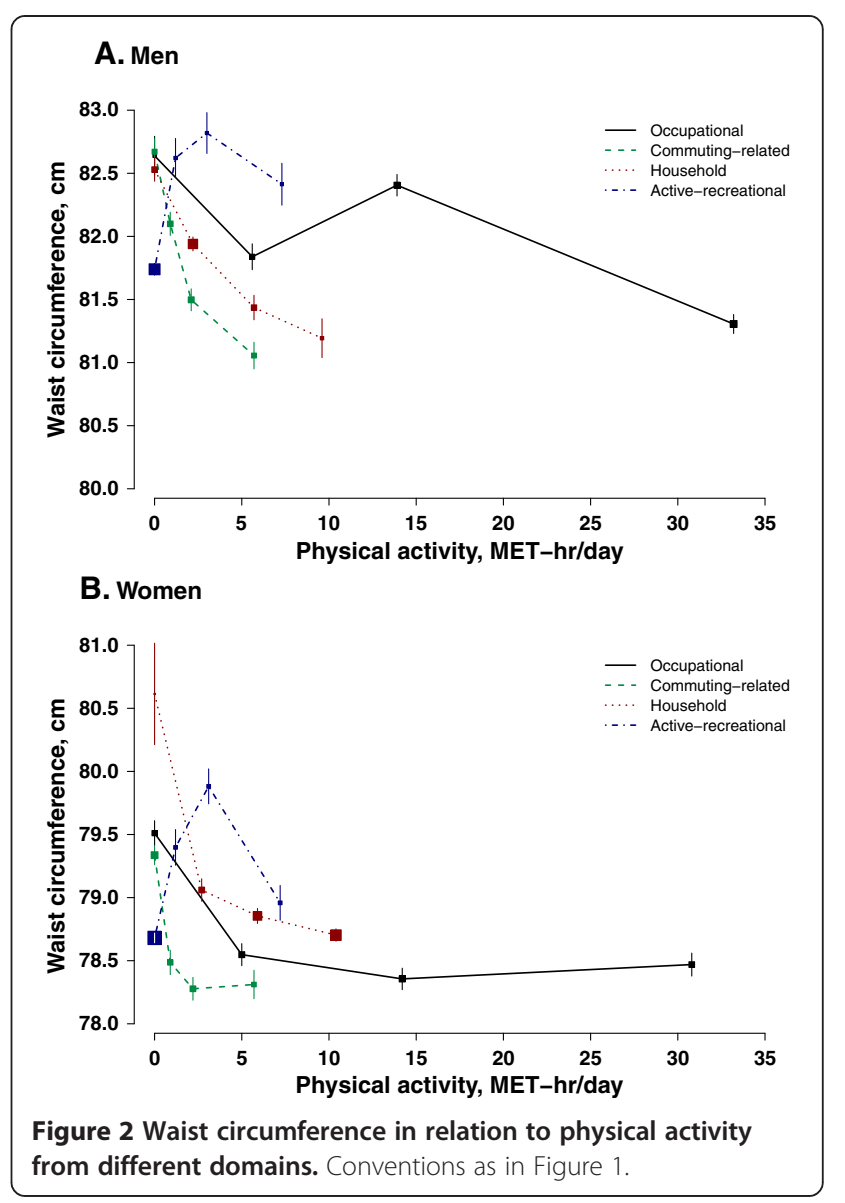

in two longitudinal studies, one involving 3500 adults from the US National Health and Nutrition Examination Survey (NHANES) [13] and one on 9400 adults in the China Health and Nutrition Survey (CHNS) [2], there was an inverse association between occupational activity and risk of obesity. But in a cross-sectional study of 12044 people in the Spanish National Health Survey, neither BMI nor risk of obesity was significantly associated with level of work-related physical activity [12]. In another crosssectional study of 1745 Swedish adults, there was a positive association of occupational physical activity with adiposity in women, but not in men [14]. Conversely, in a study among 1978 Vietnamese, an inverse association was observed only in men but not in women [29]. Disparities between these findings might be due to differences in study populations and methodologies used to assess occupational activity. Moreover, residual confounding by other factors, such as work-related stress and dietary habits, might also be an explanation for the lack of association between occupational activity and adiposity in our and other studies.

Another counterintuitive finding was that participants who engaged in regular active-recreational activities had higher, instead of lower, adiposity levels than those who did not. Reporting bias might be an explanation for this 


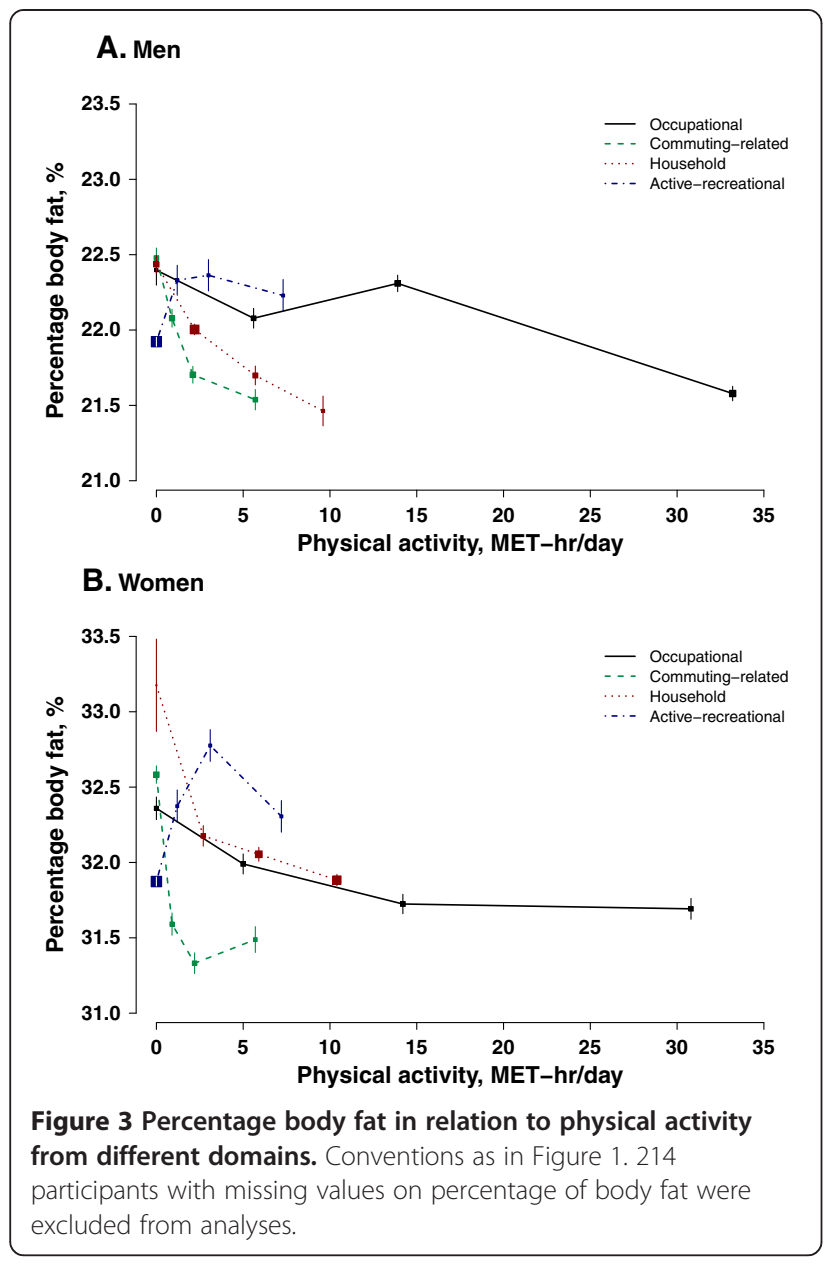

as it is known that people with a higher BMI tend to over-report the amount of exercise they performed to a greater extent than those with an 'optimal' body weight [30]. On the other hand, overweight and obese people may have started exercise more in order to control their body weight. However, this 'reverse causality' cannot be investigated reliably in the present cross-sectional analysis.

As in the present study, several previous studies have also reported an inverse association between household activity and adiposity in different populations [23,31]. In a large national cohort study of over 70000 Thai adults, the risk of being obese was 33\% lower in participants who reported doing daily household activities than those who never or rarely did so [31]. In another study of 686 Malay participants, those with the lowest amount of household activity had double the risk of obesity compared to those with the highest amount [23]. In our study, women on average spent about 2.7 hours on householdrelated tasks, compared with only about 1 hour for men. If men could on average spend one extra hour daily on similar activities (2.8 MET-hr/day), i.e. switching from sedentary leisure time, then their adiposity indices would improve by $0.1 \mathrm{~kg} / \mathrm{m}^{2}, 0.37 \mathrm{~cm}$ and 0.17 percentage point lower respectively, independent of the effects of reduced sedentary leisure time [17].

As in other similar large-scale epidemiological studies, the present study used a questionnaire to assess levels of physical activity from all domains. Compared to more objective measures of physical activity (such as accelerometers) [32], questionnaire-assessed activities are more prone to measurement error due to recall bias (particularly among the elderly), social desirability bias, and difficulties associated with capturing low-intensity activities. In addition, misclassification might have occurred because the same MET value, from a compendium of MET values which mainly came from Western studies [33], being assigned to each type of activity regardless of between-person differences in intensity of performance. Physical activity questionnaires, however, remain as the most practical, feasible and cost-effective methods for quantifying habitual physical activity from different domains in large-scale epidemiological studies involving free-living participants [34]. Although no separate validation study has been conducted on our questionnaire, the observed associations between physical activity and socio-demographic factors in our study provide support for the validity of our physical activity questionnaire.

\section{Conclusions}

In Chinese adults, physical activity was derived mainly from occupation and housework, with active-recreational activity accounting for only a small proportion of total physical activity. Domain-specific physical activity varied by socio-demographic factors (such as sex, age, and socioeconomic status), and also had different associations with adiposity. Our findings may suggest that as well as total physical activity it is important to consider physical activity from different domains when assessing their health-related effects and recommending strategies for public health interventions. In particular, household and commutingrelated activity (such as cycling) should be more widely publicized as effective ways for weight control. The continuation of the follow up for a wide range of healthrelated outcomes in the CKB participants will soon allow for the prospective assessment of the effects of total and domain-specific activities on risks of chronic diseases. Findings from prospective studies will further inform the development of public health policies on physical activity in China and other low- and middle-income countries where chronic disease burden is increasing.

\section{Additional files}

Additional file 1: Figure S1. Levels of physical activity from different domains across 10 study areas. U: Urban areas; R: Rural areas. Levels of physical activity in each area was adjusted for age (in 5-year intervals). 
Additional file 2: Figure S2. Commuting-related and household activity with BMl, waist circumference and percentage body fat in men. Associations were expressed as the regression coefficients (B) for 3 MET$\mathrm{hr} /$ day; Overall associations were estimated as inverse-variance-weighted averages. Analyses were adjusted for age, study area, education, income, sedentary leisure time, smoking, alcohol intake and other domain-specific activities. Only participants with some physical activity were included in analyses.

Additional file 3: Figure S3. Household activity with BMI, waist circumference and percentage body fat in 276078 women. Conventions as in Additional file 2: Figure S2.

\section{Abbreviations}

BMI: Body mass index; CKB: China Kadoorie Biobank; MET: Metabolic equivalent; WC: Waist circumference.

\section{Competing interests}

The authors declare that they have no competing interests.

\section{Authors' contributions}

HD performed the data analysis and wrote the manuscript; DB and PS helped with the statistical analyses and graphing; GW, DB and ZC contributed to the conception of this paper, helped with the interpretation of the results, and gave critical comments on the manuscript; LL, JC, RC, RP and ZC designed the study, obtained the funding, and contributed to the acquisition of data; and $Y G, Z B$, $\mathrm{YH}, \mathrm{NZ}, \mathrm{XZ}, \mathrm{ZL}$ and RH contributed to the data acquisition. All authors have read and approved the final manuscript, except for the deceased GW who had commented on the sub-final version of the manuscript. HD had full access to all of the data in the analysis and takes responsibility for the integrity of the data and the accuracy of the data analysis.

\section{Acknowledgements}

We thank Judith MacKay in Hong Kong; Yu Wang, Gonghuan Yang, Zhengfu Qiang, Lin Feng, Maigen Zhou, Wenhua Zhao and Yan Zhang in China CDC; Lingzhi Kong, Xiucheng Yu and Kun Li in the Ministry of Health of China; and Yiping Chen, Sarah Clark, Martin Radley, Hongchao Pan, Jill Boreham, and Sarah Lewington in the Clinical Trial Service Unit and Epidemiological studies Unit (CTSU), Oxford, for assisting with the design, planning, organization, conduct of the study and data analysis. The most important acknowledgement is to the participants in the study and the members of the survey teams in each of the 10 regional centres, as well as to the project development and management teams based at Beijing, Oxford and the 10 regional centres. CTSU acknowledges support from the British Heart Foundation Centre of Research Excellence, Oxford.

Members of China Kadoorie Biobank collaborative group are as follows: International Co-ordinating Centre, Oxford: Zhengming Chen, Garry Lancaster, Xiaoming Yang, Alex Williams, Margaret Smith, Ling Yang, Yumei Chang, Iona Millwood, Yiping Chen, Sarah Lewington

National Co-ordinating Centre, Beijing: Yu Guo, Zheng Bian, Can Hou, Yunlong Tan

Regional Co-ordinating Centres, 10 areas in China:

Qingdao

Qingdao CDC: Zengchang Pang, Shanpeng Li, Shaojie Wang Licang CDC: Silu Lv

Heilongjiang

Provincial CDC: Zhonghou Zhao, Shumei Liu, Zhigang Pang

Nangang CDC: Liqiu Yang, Hui He, Bo Yu

Hainan

Provincial CDC: Shanqing Wang, Hongmei Wang

Meilan CDC: Chunxing Chen, Xiangyang Zheng

Jiangsu

Provincial CDC: Xiaoshu Hu, Minghao Zhou, Ming Wu, Ran Tao

Suzhou CDC: Yeyuan Wang, Yihe Hu, Liangcai Ma

Wuzhong CDC: Renxian Zhou

Guangxi

Provincial CDC: Zhenzhu Tang, Naying Chen, Ying Huang

Liuzhou CDC: Mingqiang Li, Zhigao Gan, Jinhuai Meng, Jingxin Qin

Sichuan

Provincial CDC: Xianping Wu, Ningmei Zhang

Pengzhou CDC: Guojin Luo, Xiangsan Que, Xiaofang Chen
Gansu

Provincial CDC: Pengfei Ge, Xiaolan Ren, Caixia Dong

Maiji CDC: Hui Zhang, Enke Mao, Zhongxiao Li

Henan

Provincial CDC: Gang Zhou, Shixian Feng

Huixian CDC: Yulian Gao, Tianyou He, Li Jiang, Huarong Sun

Zhejiang

Provincial CDC: Min Yu, Danting Su, Feng Lu

Tongxiang CDC: Yijian Qian, Kunxiang Shi, Yabin Han, Lingli Chen

Hunan

Provincial CDC: Guangchun Li, Huilin Liu, Li Yin

Liuyang CDC: Youping Xiong, Zhongwen Tan, Weifang Jia

\section{Funding}

The China Kadoorie Biobank study is sponsored by the Kadoorie Charitable Foundation in Hong Kong, China, the Wellcome Trust in the UK, the UK Medical Research Council (MRC), the British Heart Foundation, Cancer Research UK, and the National Key Technology Research and Development Program in the 12th Five-Year Plan, Ministry of Science and Technology, People's Republic of China (Ref: 2011BAI09B01). The funders had no role in study design, data collection and analysis, decision to publish, or preparation of the manuscript. The members of the steering committee and collaborative group of the China Kadoorie Biobank are listed in the Acknowledgement section

\section{Author details}

${ }^{1}$ Clinical Trial Service Unit and Epidemiological Studies Unit (CTSU), Nuffield Department of Population Health, University of Oxford, Oxford, UK. ${ }^{2}$ School of Public Health, Peking University Health Sciences Center, Beijing, China. ${ }^{3}$ Chinese Academy of Medical Sciences, Beijing, China. ${ }^{4}$ China National Center for Food Safety Risk Assessment, Beijing, China. ${ }^{5}$ Non-Communicable Disease Prevention and Control Department, Provincial Center for Disease Control, Guangxi Zhuang Autonomous Region, China. ${ }^{6}$ Non-Communicable Disease Prevention and Control Department, Provincial Center for Disease Control, Sichuan Province, China. ${ }^{7}$ Non-Communicable Disease Prevention and Control Department, Meilan Center for Disease Control, Hainan Province, China. ${ }^{8}$ Non-Communicable Disease Prevention and Control Department, Maiji Center for Disease Control, Tianshui, Gansu Province, China.

${ }^{9}$ Administration office, Provincial Center for Disease Control, Zhejiang Province, China.

Received: 26 February 2014 Accepted: 29 July 2014

Published: 9 August 2014

\section{References}

1. O'Donovan G, Blazevich AJ, Boreham C, Cooper AR, Crank H, Ekelund U, Fox KR, Gately P, Giles-Corti B, Gill JM, Hamer M, McDermott I, Murphy M, Mutrie N, Reilly JJ, Saxton JM, Stamatakis E: The ABC of Physical Activity for Health: a consensus statement from the British Association of Sport and Exercise Sciences. J Sports Sci 2010, 28:573-591.

2. Monda KL, Adair LS, Zhai F, Popkin BM: Longitudinal relationships between occupational and domestic physical activity patterns and body weight in China. Eur J Clin Nutr 2008, 62:1318-1325.

3. Ng SW, Norton EC, Popkin BM: Why have physical activity levels declined among Chinese adults? Findings from the 1991-2006 China Health and Nutrition Surveys. Soc Sci Med 2009, 68:1305-1314.

4. Bauman A, Allman-Farinelli M, Huxley R, James WP: Leisure-time physical activity alone may not be a sufficient public health approach to prevent obesity-a focus on China. Obes Rev 2008, 9(Suppl 1):119-126.

5. Bauman AE, Reis RS, Sallis JF, Wells JC, Loos RJ, Martin BW: Correlates of physical activity: why are some people physically active and others not? Lancet 2012, 380:258-271.

6. Trost SG, Owen N, Bauman AE, Sallis JF, Brown W: Correlates of adults' participation in physical activity: review and update. Med Sci Sports Exerc 2002, 34:1996-2001.

7. Bauman A, Ma G, Cuevas F, Omar Z, Waqanivalu T, Phongsavan P, Keke K, Bhushan A: Cross-national comparisons of socioeconomic differences in the prevalence of leisure-time and occupational physical activity, and active commuting in six Asia-Pacific countries. J Epidemiol Community Health 2011, 65:35-43. 
8. Jurj AL, Wen W, Gao YT, Matthews CE, Yang G, Li HL, Zheng W, Shu XO: Patterns and correlates of physical activity: a cross-sectional study in urban Chinese women. BMC Public Health 2007, 7:213.

9. Hu G, Pekkarinen H, Hanninen O, Yu Z, Guo Z, Tian H: Commuting, leisuretime physical activity, and cardiovascular risk factors in China. Med Sci Sports Exerc 2002, 34:234-238.

10. Millett C, Agrawal S, Sullivan R, Vaz M, Kurpad A, Bharathi AV, Prabhakaran D, Reddy KS, Kinra S, Smith GD, Ebrahim S: Associations between Active Travel to Work and Overweight, Hypertension, and Diabetes in India: A CrossSectional Study. PLoS Med 2013, 10:e1001459.

11. Gordon-Larsen P, Boone-Heinonen J, Sidney S, Sternfeld B, Jacobs DR Jr, Lewis CE: Active commuting and cardiovascular disease risk: the CARDIA study. Arch Intern Med 2009, 169:1216-1223.

12. Gutierrez-Fisac JL, Guallar-Castillon P, Diez-Ganan L, Lopez Garcia E, Banegas Banegas JR, Rodriguez Artalejo F: Work-related physical activity is not associated with body mass index and obesity. Obes Res 2002, 10:270-276.

13. Steeves JA, Bassett DR Jr, Thompson DL, Fitzhugh EC: Relationships of occupational and non-occupational physical activity to abdominal obesity. Int J Obes (Lond) 2012, 36:100-106.

14. Larsson CA, Kroll L, Bennet L, Gullberg B, Rastam L, Lindblad U: Leisure time and occupational physical activity in relation to obesity and insulin resistance: a population-based study from the Skaraborg Project in Sweden. Metabolism 2012, 61:590-598.

15. Chen Z, Lee L, Chen J, Collins R, Wu F, Guo Y, Linksted P, Peto R: Cohort profile: the Kadoorie Study of Chronic Disease in China (KSCDC). Int J Epidemiol 2005, 34:1243-1249.

16. Chen Z, Chen J, Collins R, Guo Y, Peto R, Wu F, Li L: China Kadoorie Biobank of 0.5 million people: survey methods, baseline characteristics and long-term follow-up. Int J Epidemiol 2011, 40:1652-1666.

17. Du H, Bennett D, Li L, Whitlock G, Guo Y, Collins R, Chen J, Bian Z, Hong LS, Feng S, Chen X, Chen L, Zhou R, Mao E, Peto R, Chen Z: Physical activity and sedentary leisure time and their associations with BMI, waist circumference, and percentage body fat in 0.5 million adults: the China Kadoorie Biobank study. Am J Clin Nutr 2013, 97:487-496.

18. Wareham NJ, Jakes RW, Rennie KL, Mitchell J, Hennings S, Day NE: Validity and repeatability of the EPIC-Norfolk Physical Activity Questionnaire. Int J Epidemiol 2002, 31:168-174.

19. Matthews CE, Shu XO, Yang G, Jin F, Ainsworth BE, Liu D, Gao YT, Zheng W: Reproducibility and validity of the Shanghai Women's Health Study physical activity questionnaire. Am J Epidemio/ 2003, 158:1114-1122.

20. Ainsworth BE, Haskell WL, Herrmann SD, Meckes N, Bassett DR Jr, TudorLocke C, Greer JL, Vezina J, Whitt-Glover MC, Leon AS: Compendium of Physical Activities: a second update of codes and MET values. Med Sci Sports Exerc 2011, 2011(43):1575-1581.

21. Higgins JP, Thompson SG, Deeks JJ, Altman DG: Measuring inconsistency in meta-analyses. BMJ 2003, 327:557-560.

22. Lee SA, Xu WH, Zheng W, Li H, Yang G, Xiang YB, Shu XO: Physical activity patterns and their correlates among Chinese men in Shanghai. Med Sci Sports Exerc 2007, 39:1700-1707.

23. Chu AH, Moy FM: Associations of occupational, transportation, household and leisure-time physical activity patterns with metabolic risk factors among middle-aged adults in a middle-income country. Prev Med 2012, doi:10.1016/j.ypmed.2012.1012.1011

24. Khaing Nang EE, Khoo EY, Salim A, Tai ES, Lee J, Van Dam RM: Patterns of physical activity in different domains and implications for intervention in a multi-ethnic Asian population: a cross-sectional study. BMC Public Health 2010, 10:644.

25. Martinez-Gonzalez MA, Martinez JA, Hu FB, Gibney MJ, Kearney J: Physical inactivity, sedentary lifestyle and obesity in the European Union. Int J Obes (Lond) 1999, 23:1192-1201.

26. Haskell WL, Lee IM, Pate RR, Powell KE, Blair SN, Franklin BA, Macera CA, Heath GW, Thompson PD, Bauman A: Physical activity and public health: updated recommendation for adults from the American College of Sports Medicine and the American Heart Association. Circulation 2007, 116:1081-1093.

27. Collins R: What makes UK Biobank special? Lancet 2012, 379:1173-1174.

28. Manolio TA, Collins R: Enhancing the feasibility of large cohort studies. JAMA 2010, 304:2290-2291.

29. Thuy AB, Blizzard L, Schmidt MD, Pham LH, Granger RH, Dwyer T: Physical activity and its association with cardiovascular risk factors in Vietnam. Asia Pac J Public Health 2012, 24:308-317.
30. Slootmaker SM, Schuit AJ, Chinapaw MJ, Seidell JC, van Mechelen W: Disagreement in physical activity assessed by accelerometer and selfreport in subgroups of age, gender, education and weight status. Int J Behav Nutr Phys Act 2009, 6:17.

31. Banks E, Lim L, Seubsman SA, Bain C, Sleigh A: Relationship of obesity to physical activity, domestic activities, and sedentary behaviours: crosssectional findings from a national cohort of over 70,000 Thai adults. BMC Public Health 2011, 11:762.

32. Jimenez-Pavon D, Konstabel K, Bergman P, Ahrens W, Pohlabeln $H$, Hadjigeorgiou C, Siani A, lacoviello L, Molnar D, De Henauw S, Pitsiladis Y, Moreno LA: Physical activity and clustered cardiovascular disease risk factors in young children: a cross-sectional study (the IDEFICS study). BMC Med 2013, 11:172.

33. Ng SW, Popkin BM: Time use and physical activity: a shift away from movement across the globe. Obes Rev 2012, 13:659-680.

34. Haskell WL: Physical activity by self-report: a brief history and future issues. J Phys Act Health 2012, 9(Suppl 1):S5-S10.

doi:10.1186/1471-2458-14-826

Cite this article as: Du et al:: Patterns and socio-demographic correlates of domain-specific physical activities and their associations with adiposity in the China Kadoorie Biobank study. BMC Public Health 2014 14:826.

\section{Submit your next manuscript to BioMed Central and take full advantage of:}

- Convenient online submission

- Thorough peer review

- No space constraints or color figure charges

- Immediate publication on acceptance

- Inclusion in PubMed, CAS, Scopus and Google Scholar

- Research which is freely available for redistribution 